\title{
Challenges in Teaching Japanese EFL Students to Express Themselves Logically
}

\author{
Reiko Okada ${ }^{1}$ \\ ${ }^{1}$ Liberal Arts Education Center, Takanawa Campus, Tokai University, Tokyo, Japan \\ Correspondence: Reiko Okada, Liberal Arts Education Center, Takanawa Campus, Tokai University, 2-3-23 \\ Takanawa, Minato-Ku, Tokyo 108-8619 Japan.
}

Received: February 22, 2018

Accepted: March 6, 2018

Online Published: March 9, 2018

doi:10.20849/aes.v3i1.335

URL: https://doi.org/10.20849/aes.v3i1.335

\begin{abstract}
This paper describes a study conducted with twenty-five Japanese lower-level EFL students to develop their ability to write logically in English. In school, Japanese students rarely express their opinions in writing supported by facts or reasons, a result of an important characteristic of Japanese culture: people focus more on emotion than on critical reasoning. Teachers of English often instruct students to add reasons, examples, or conclusions to their written expressions of opinion, but students often fail to do so because they do not grasp their purpose. In this study, students were explicitly instructed in 1) the different values in Western and Japanese culture, 2) alternate ways of thinking and expression, 3) the importance of logic in English rhetoric, and 4) paragraph structure in written English. Students practice writing using English paragraph structure, first in Japanese and then in English. The results indicated that initially only about one third of the students acquired an understanding of how to organize a paragraph logically when writing in Japanese, indicating the difficulty Japanese students have in adopting the principles of English rhetoric even in their native language. After explicit instructions were given repeatedly, another one third of the students were able to structure their paragraphs logically when writing in English. Throughout the six sessions of the study, however, the rest of the students $(32 \%)$ continued to write their paragraphs in both Japanese and English according to the conventions of Japanese rhetoric, or without logical reasoning.
\end{abstract}

Keywords: EFL writing, Japanese to English, contrastive rhetoric, critical thinking, culture

\section{Introduction}

The twenty-first-century skills defined by ATC21S include communication and collaboration in the category of "ways of working", and critical thinking and decision-making in the category of "ways of thinking". In Japanese education, however, neither communication ability nor critical thinking ability has been taught successfully. Although English is the dominant language of communication and collaboration in the global community in the twenty-first century, it is very difficult for Japanese people to master. The primary reason is that Japan is a homogeneous, monolingual nation, and the Japanese have little exposure to English or need to use it in their daily lives (Yoshida, 2008). In addition, compared with the other major languages used in the world now, such as French, Russian, Chinese, and Korean, English is said to be furthest from Japanese (Ohtani, 2007). Another reason is that critical thinking, which is rooted in Western society and which is something like "common sense" in North American society (Atkinson, 1997), is very foreign and unfamiliar to Japanese people, who consider assertive expressions with logic and reasoning to be impolite and arrogant, since "cooperativeness, ... and understanding of others are the virtues most admired, not ... individual self-assertion" (Reischauer, p.135). Native English speakers teaching in Japan are often surprised to find that Japanese students have not been taught how to think logically and express themselves critically (Davidson, 1995, Stapleton, 2002, McKinley, 2013, Mulvey, 2016). Although both English linguistic ability and critical thinking ability are key skills for success in this rapidly changing global community, neither is taught effectively in Japan (Yoshida, 2008, National Institute for Educational Policy Research in Japan, 2014, Okada, 2016, National Institution for Youth Education, 2017).

Within the limited English learning environment, teachers of English in Japan have been struggling to decide what and how to teach. Yoshida (2013) proposed that English classes in Japan should focus on academic English rather than on daily conversation and transactions, because daily conversation can be acquired by spending time in an English-speaking environment and interacting with native speakers; on the other hand, academic English, 
which includes critical thinking, cannot be acquired without instruction, so it should be learned in an academic setting. Today's technological development has brought about more reliable translation software, yet structuring larger units than words and sentences, such as paragraphs and ideas, is more important and requires human reasoning ability.

We often hear native-speaking English teachers in Japan say that "Japanese students ... fit the stereotypes of being passive and non-participatory, with little ability in ... critical enquiry" (Rear, 2012). However, perhaps they are unable to think critically only because they are not educated to do so. Typically, Japanese students are not taught explicitly how people from other cultures think and act or what we need to know to communicate with them beyond simple linguistic ability. To test this theory, I conducted a study with Japanese EFL students to learn whether they can be taught to express themselves logically when they are instructed explicitly why it is necessary and how to do it. In this paper, I will describe the difficulties Japanese EFL students encounter in writing in English, explain the study conducted with lower-proficiency EFL students in a Japanese university, discuss what students were able to learn with a more comprehensive approach to teaching English writing, and discuss the implications of the study for the teaching of English to Japanese students.

\section{Problems in Japanese Students' Writing}

In school, Japanese students are often asked to write about their experiences in journals and give their personal impressions of materials read, but they rarely practice expository or argumentative writing (Hirose, 2003). This causes problems for Japanese students in writing in English. First, they tend to explain things randomly and focus on their emotional reactions. Second, they tend to express things ambiguously, without detailed facts or reasons, because of a Japanese cultural tendency to avoid being logical or critical, so as to avoid conflict.

Sample 1 below was written by a university freshman and lower-level EFL student after reading easy graded readers each week during a fifteen-week semester. In each instance the student wrote very short answers without explaining in detail. Furthermore, she did not realize the importance of the teacher's comments, such as "Why?", "because he...", and "for example?", which implied that reasons and details are necessary when expressing written opinions in English.

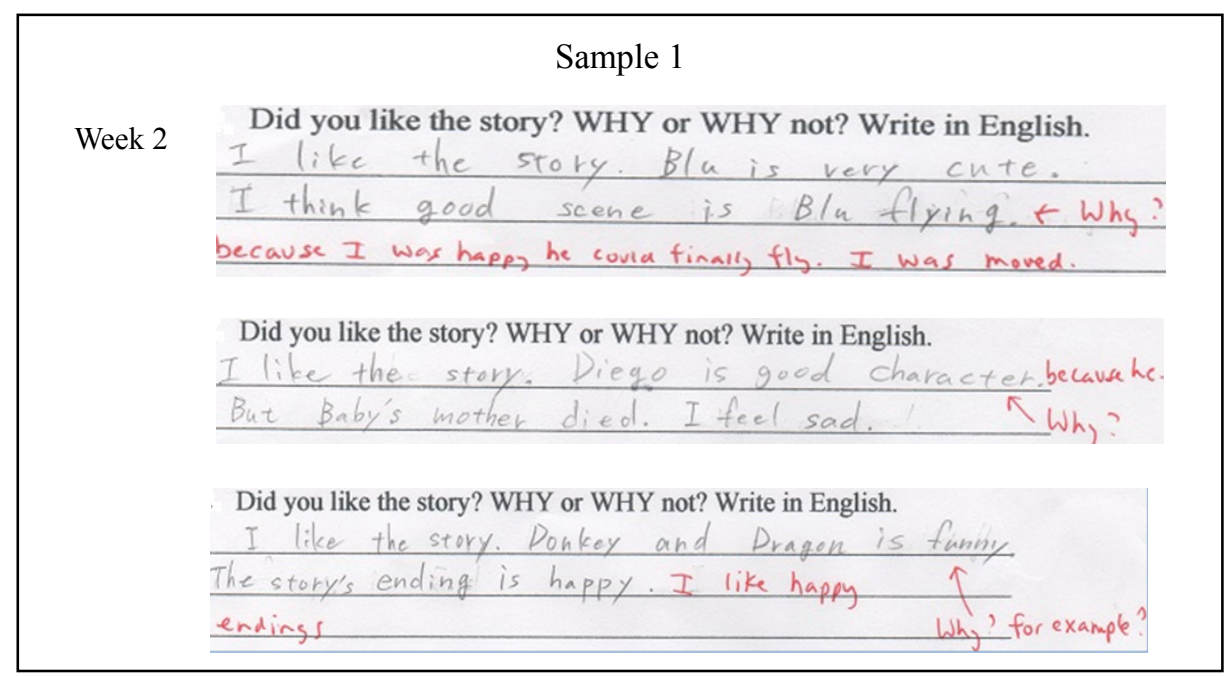

Sample 2 also shows a typical writing by a Japanese university freshman, in answer to the question "Which is better as a pet, a dog or a cat?" The student wrote whatever came to mind, subjectively and randomly, and without factual reasons. Obviously, as Mulvey (2016) stated, "[e]ssay organizational strategies, recognizing and applying critical analysis, and using factual or scholarly support for opinions are not covered in the typical Japanese high school classroom" (p.5).

\footnotetext{
$\underline{\text { Sample } 2}$

My opinion is that a dog is better than a cat. Because I don't like a cat and I have three dogs. Cats are cute but their tails are dangerous and it is difficult for us to take care of them in the home. But dogs stay at home every day so they make me happy.
} 
Both samples indicate that students only transferred to English the conventions of Japanese rhetoric--in which "people pay greater attention to ... human emotions and place less emphasis on instrumental results" (Oi, 1999, p.90)--because they had not learned the conventions of English rhetoric or the fact that "each language and each culture has a paragraph order unique to itself" (Kaplan, 1966, p.14).

\section{Purpose of the Study}

The globalized world of the twenty-first century demands not only English linguistic ability but also the ability to express oneself logically. Therefore, I hypothesized as follows: by receiving explicit instruction in the difference between expression in English and in Japanese and the necessity of using the standards of English rhetoric, and by practicing writing using English rhetoric in Japanese, students will learn to express opinions logically in both English and Japanese.

\section{Procedure of the Study}

\subsection{Participants}

Twenty-five Japanese university freshmen from two EFL "Reading \& Writing 1" classes participated in this study. The students' English proficiency level was that of upper beginners.

\subsection{Context of the Study}

The participants studied English reading and writing using a textbook, Grammar Connection 2 (Cengage, 2008). The course was scheduled under a unified syllabus for 15 weeks. This study was conducted during the spring semester in 2016 in six consecutive sessions given as extra activities, using about thirty minutes of a ninety-minute period each time.

\subsection{Instructions and Assignments}

The first six sessions of the semester were used for this study. They consisted of three stages: raising awareness of different cultures, learning English paragraph structure, and practicing writing opinions in English. The activities given in each session are shown in Table 1 .

Table 1. Instructions and assignments

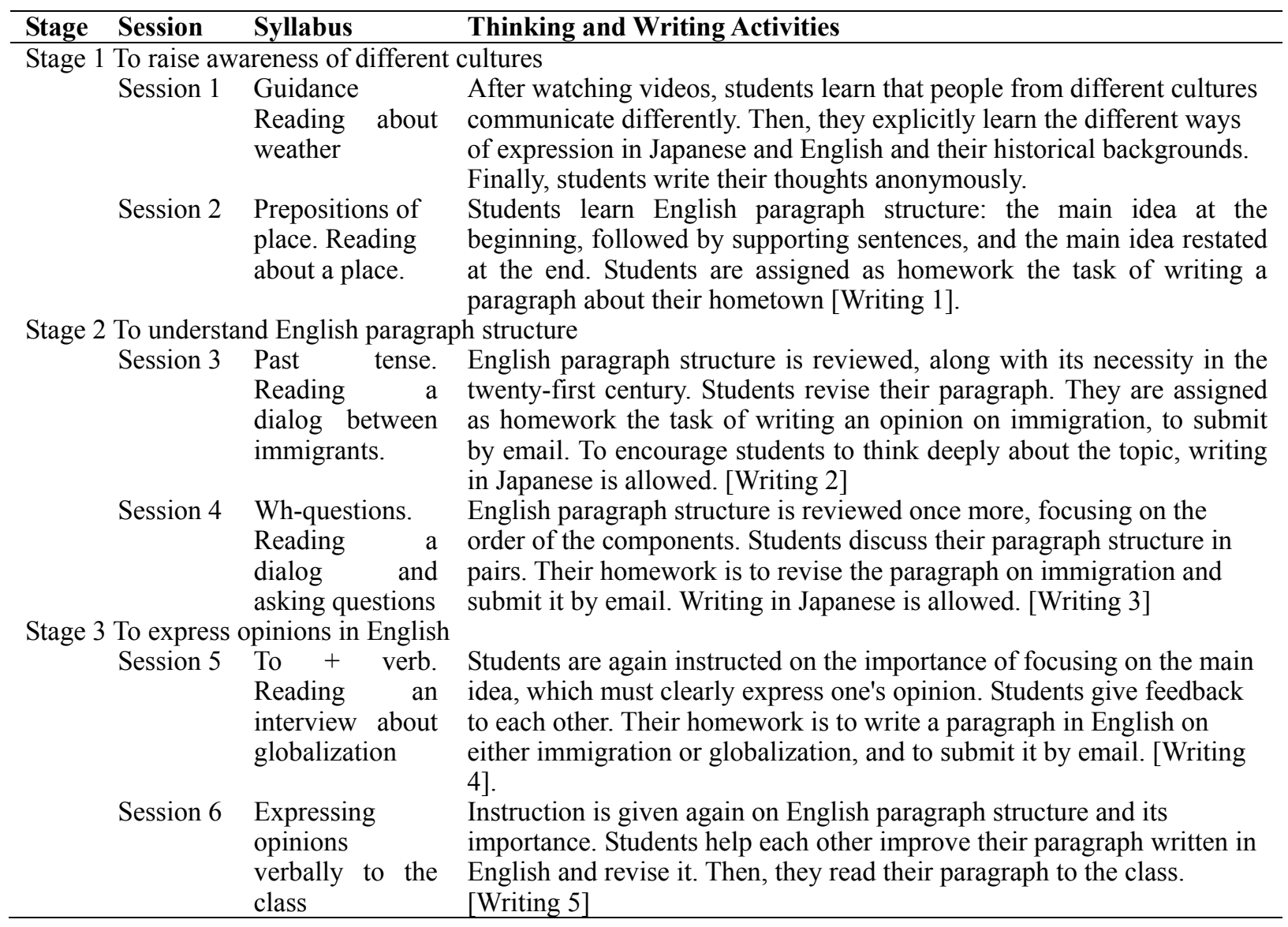


In the first session, students watched twelve interviews with people from a variety of cultural backgrounds who answered the question, "What would you do if a person upstairs in your apartment house made noise late at night and you could not sleep?" The interviewees from UK, Australia, Canada, Saudi Arabia, Laos, and China answered that they would politely ask the person upstairs to be quiet and explain the reason for their request. On the other hand, the interviewees from Thailand, India, Sri Lanka and Japan answered that they would not say anything directly to the person upstairs. Following the video, the students were given a short lecture on different cultural styles and their histories, to help them understand explicitly that people of different cultures have different ways of expressing themselves. Students' feedback was collected.

In the second session, students reviewed the previous session about cultural and rhetorical differences, focusing on the uniqueness of Japanese rhetoric; then they were instructed in the conventions of English paragraph structure. They were assigned as homework the task of writing a paragraph in the logical structure in English.

In the third session, students checked the structure of their paragraph following the teacher's instruction: they underlined the main idea at the beginning and at the end, numbered the sentences which supported the main idea, and crossed off unnecessary sentences or added additional sentences. Samples $3 \mathrm{a}$ and $3 \mathrm{~b}$ illustrate how Student A learned the basic structure of a paragraph written in English. Although there are many grammatical mistakes and expressions hard to understand, they are shown as was written by Student A.

\section{Sample 3a (Writing 1 by Student A, written in English and shown as was written)}

My town is in Kawaguchi City, one of the developed industry areas in Saitama. There are many factories everywhere. For example, Imono factory, place of garden plant. There are place of garden plant near my home. That area is Angyo town. It is famous for garden plant in Japan. And famous Imono in Kawasaki City is platform bearing the Olympic flame. This is in big park far from my home. When I pass in front of it, I feel the greatness of Kawaguchi City's industry.

\footnotetext{
Sample $3 \mathrm{~b}$ (Revision of Writing 1 by Student A)

My town is in Kawaguchi City, one of the develop industry area in Saitama. ${ }^{(1)}$ There are many factory everywhere. For example, Imono factory, place of garden plant. There are place of garden plant near my home. That area is Angyo town. It is famous for garden plant in Japan. ${ }^{2}$ And Imono in Kawasaki City is platform bearing the Olympic flame. This is in big park far from my home. When I pass in front of it, I feel the greatness of Kawaguchi City's industry.

*Notes: Delete words about plants. Write more about Imono industry, Something found only in Kawaguchi, with characteristic examples.

(*Notes were written by Student A while listening to the instruction, originally written in Japanese and translated by the author.)
}

Students were assigned as homework the task of writing their opinion on immigration. Since the topic seemed difficult and needed deep thinking, they were allowed to use Japanese.

In the following three sessions, the differences between Japanese rhetoric and English rhetoric were explicitly reviewed, and writing or revising the paragraph according to English paragraph structure was assigned for homework. In total, four paragraphs (Writings 2, 3, 4 and 5) were submitted by email.

\subsection{Data Collection}

Feedback from the first session and the four paragraphs submitted were collected and analyzed. The first paragraph (Writing 1) was not collected, since the instruction was brief, the activity was totally new, and students did not appear confident enough to show it to the instructor. (Only Student A's Writing 1 above was submitted because he needed to hand in other homework in his notebook.)

\section{Results and Discussion}

\subsection{Awareness of Cultural Differences}

Samples 4, 5, 6, 7 and 8 below represent students' feedback submitted after the first session. (They were originally written in Japanese and translated by the author.) 


\section{$\underline{\text { Sample } 4}$}

I am not good at talking to other people. So when I need to talk, I usually keep it short and leave things unclear. But I have realized that explaining things clearly is necessary when I work globally as an engineer...

$\underline{\text { Sample } 5}$

I realized that we say important things at the end in Japanese, while in English important things should be spoken at the beginning. I think it is important to be aware of differences between countries and to see ourselves objectively when we communicate in the world of the future....

$\underline{\text { Sample } 6}$

In western countries, they say "Yes" or "No" clearly, but Japanese people say "Yes", "No", or "Either". Maybe "Either" is not a choice in logical thinking.

\section{$\underline{\text { Sample } 7}$}

I was once scolded by an English teacher and I didn't understand why. Now I understand that words and acts which don't mean much to me could make people from other cultures resentful... .

$\underline{\text { Sample } 8}$

I don't try to talk much to make myself understood in my daily life. So when I started studying English, I wondered why I must say reasons and conclusions each time. But now I understand that I must say important things in detail to communicate in the world, and also, both Japanese and Western people should be polite when we communicate.

Samples 4, 5 and 6 indicate that the students realized that what they take for granted cannot always be assumed in the global community, and that their daily communication style with fellow Japanese cannot be applied when they communicate in the world. In Samples 7 and 8, we see that students have found answers for things that once confused them in their experience in the English-language classroom.

These samples demonstrate that students are not always taught explicitly that different cultures have different ways of conveying meaning and that we cannot automatically transfer Japanese communication style to communication in English, because the two languages reflect different values of logic and emotion.

\subsection{Understanding and Applying the Logical Paragraph Structure}

Each student's four paragraphs (Writing 2, 3, 4 and 5) were rated, with one being the lowest score and five being the highest. Figure 1 shows the average score of each writing of 25 students in terms of the order of components in the paragraph: the main idea first, followed by supporting sentences, and then a closing sentence. Figure 2 shows the average score of supporting sentences of 25 students in terms of whether they give information to support the main idea properly.

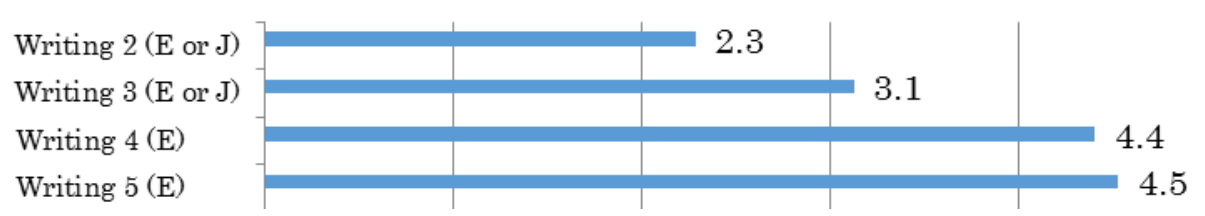

Figure 1. Average score of the component order

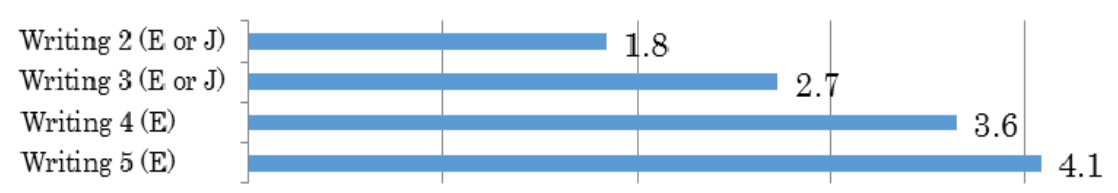

Figure 2. Average score of the supporting sentences

Figures 1 and 2 point to two important conclusions. First, the number of students who understood English 
paragraph structure and could apply it in their writing increased gradually as they were repeatedly given explicit instruction. Second, students learned how to order the components of the paragraph more easily than they learned how to support the main idea.

Figure 3 indicates for each assignment the percentage of students who for the first time were able to write in English using correct English paragraph structure.

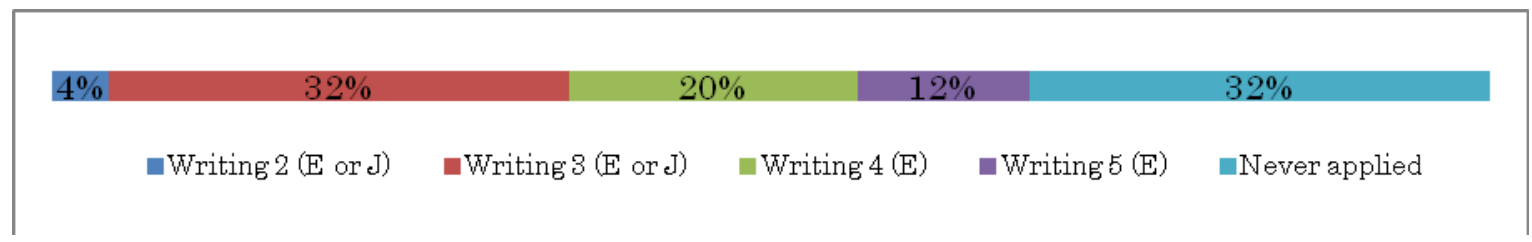

Figure 3. For each assignment, the percentage of students who for the first time were able to write in English using correct English paragraph structure

Figure 3 reveals that (1) very few students (4\%) wrote using English paragraph structure in writing 2 (after receiving explicit instruction twice), (2) the third instruction helped one third (32\%) of the students to understand what is required for logical writing and to apply it in their writing, (3) for students who could write a paragraph using English structure in Writings 2 and 3, even for the majority who wrote in Japanese, they were able to express themselves logically although Japanese writing traditionally does not favor critical reasoning, and (4) despite explicit instruction and writing practice, another one third (32\%) of students did not learn to structure a paragraph logically either in English or Japanese.

\subsection{Sample Analysis}

Findings from careful examination of each student's paragraphs are as follows:

\subsubsection{Ambiguous, Circular Paragraph}

In Writing 2 on "immigration," which required deep thinking, students were allowed to write in Japanese. However, only one student (4\%) could organize a paragraph using English structure. Using Japanese, students could write a long, detailed paragraph, but they did not apply what they were supposed to have learned about English paragraph structure while writing in Japanese. Even those who kept logical paragraph structure in mind perhaps were uncomfortable expressing an opinion logically using Japanese.

Sample 9a by Student B indicates the above possibility. (It was originally written in Japanese and translated by the author.) In the first sentence, Student B wrote that he disagreed with the idea of admitting immigrants to Japan, but then agreed conditionally. His explanation for his opinion was circuitous and expressed with ambiguous words, such as "two parties", "active culture", and "quiet culture". Finally, he concluded by naming "the country where such a system is not prepared", rather than directly naming Japan. Sample 9a seems to represent what Kaplan (1966) claims: English rhetoric expresses things directly, while East Asian rhetoric advances in a circular way.

Sample 9a (Writing 2 by Student B, originally written in Japanese and translated by the author)

I disagree that Japan should allow immigrants into our country. But I don't mean to oppose immigrants in general. If the country can control immigrants and have them pay taxes, I agree that we should accept immigrants. I disagree on admitting any immigrant without any control. Admitting immigrants mean accepting different cultures into the country, and conservative people will oppose that. The main reason for my opposing immigrants is that problems can happen between the two groups when people from an active culture come into a quiet one. I have heard of problems when immigrants are admitted, due to the differences between cultures. So, the country needs to prepare a system to take care of immigrants more carefully than for the people already living there. Therefore, I disagree that immigrants should be accepted into a country that is not yet prepared with such a system.

Sample $9 b$ is the revised paragraph by Student B after the explicit instruction to make it logical. He reasoned more straightforwardly by eliminating vague expressions, which made the paragraph more logical, although 
there were still some vague expressions.

$\underline{\text { Sample } 9 \mathrm{~b}}$ (Writing 3 by Student B, originally written in Japanese and translated by the author)

I disagree with immigrants to Japan. The reason is that we may have problems after accepting other cultures into the country. Actually, I have heard of problems due to cultural difference when immigrants are admitted. In my opinion, a country that accepts immigrants must prepare a system to take good care of them, and both the immigrants and the people who accept immigrants must understand each other beforehand. Therefore, right now I disagree with accepting immigrants to a country that is unprepared with such a system.

\subsubsection{Indecisive Paragraph}

Samples $10 \mathrm{a}$ and $10 \mathrm{~b}$ show how Student $\mathrm{C}$ wrote and revised his paragraphs. They were originally written in Japanese and translated by the author.

In Sample 10a, Student C started the paragraph mentioning the USA. Then, in the second sentence, he imagined immigrants' emotion by using the expression "a rich country" to hint at the USA without specifying it. The next sentence offered something like factual information that seemed to refer to the USA's situation. Every sentence so far was ambiguous. Then, at the middle of the paragraph, Student C's idea seemed to be expressed first time, followed by an example in Japan. It the end, however, an opposite opinion was expressed. Student $\mathrm{C}$ seems to have written as he usually does when writing in Japanese, not stating an opinion directly or deciding his position clearly. This is a typical Japanese way of expression, as Nakamura (1983) explains: because writers place a high value on the relationship with the reader, they fear that a message stated too straightforwardly will be read as excluding a different opinion on the reader's part; thus they often favor vague expressions.

Sample 10a (Writing 2 by Student C, originally written in Japanese and translated by the author)

When I hear "immigration", I think of the USA. If your country is poor, you want to emigrate to a rich country. And the rich country must decide whether it should accept people from outside and offer them a home. However, immigrants are needed to some extent. In a country like Japan where the working population is decreasing, immigrants are helpful. Accepting too many immigrants may cause cultural problems and safety problems.

Sample 10b shows how Student $C$ revised the paragraph after the explicit instruction the third time. It was revised by introducing an example, using connecting words such as "but" and "so", and stating the merits and demerits more clearly. However, Student C's opinion was still not stated clearly throughout the paragraph. This seems to be the result of the learning style described by Atkinson (1997): "memorization and choral recitation are promoted as major learning strategies in the classroom, ... innovation and individual creativity in writing are strongly discouraged ..." (p.83). In traditional Japanese culture, clear-cut decisions are made by a superior or a group rather than by individuals (Reischauer, 1978). This is probably the reason for Japanese students' tendency not to clearly state yes-or-no opinions. Writing a paragraph in Japanese using English structure may not be very effective for learning to write logically.

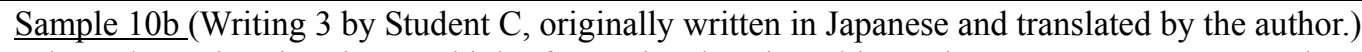

When I hear "immigration", I think of America, but the subject relates to Japan, too. Japan has a problem with depopulation and needs foreign workers. So if we accept immigrants, we can increase the working population and can solve problems such as lack of caretakers. However, large numbers of immigrants can cause problems of cultural misunderstanding and worsen public safety. There was a murder in Okinawa the other day, which escalated feelings against the American military base. These kinds of things are the disadvantages of immigration. Japan will accept more immigrants from now on, so we should understand different cultures when we communicate with them. All these affect us, so we cannot neglect this issue.

\subsubsection{Lack of Critical Thinking}

Student $\mathrm{C}$ wrote the next paragraph (Sample 10c) in English, after being instructed again and hearing peer feedback. He focused on one idea and eliminated opposing ones, so although linguistic weakness confused 
readers, such as the last sentence, he seemed to have finally learned English paragraph structure. However, the paragraph was very short and the supporting sentences did not sufficiently explain his main idea. This could be due to his low English language proficiency, or it could mean that he was not able to think and analyze the problem critically. It is likely that he had been educated in a classroom where "neither verbal ability, nor class participation ... nor the ability to write well significantly affected grades" (Fukuzawa, 1995, p.300) and where students were not allowed to doubt what was written in textbooks (Ohmae, 2003).

\title{
Sample 10c (Writing 4 by Student C, written in English)
}

Japan should accept more immigrants. Japan should increase the population. Because the population is decreasing in Japan. Japan also decreasing workers. I think that foreign workers are accepted in Japan. (Student C seems to mean "foreign workers should be accepted.")

Samples 11a (Writing 3) and 11b (Writing 4) written in English by Student D also reflect a lack of skill in asserting a definite opinion. In Sample 11a, Student D was indecisive, stating as a conclusion that "it is a difficult problem", after an incomprehensible sentence "act only in faith". After instructed to think critically and decide his own stance, in Sample 11b Student D expressed his opinion, but it was not reasoned properly, even after taking into account his linguistic weakness.

\section{Sample 11a (Writing 3 by Student D, written in English)}

Immigration problem is very difficult problem, because we should help each other. But Japan can not afford now, and they are different in culture. So we can act only in faith. So it is difficult problem.

\begin{abstract}
Sample 11b (Writing 4 by Student D, written in English)
Japan should not accept more immigrants now. It has three reasons. First, Japan has never been the multiethnic country, because they don't go to island nation Japan. If they come to Japan, we are embarrassed each other. Second, if immigrants come to Japan, more people in Japan can not work. Third, Japan is dangerous many earthquake. So Japan should not accept more immigrants now. But we should accept them when we will be able to prepare in Japan.
\end{abstract}

As Figures 1 and 2 showed, detailing the main ideas logically is more difficult than ordering components logically because the former requires higher thinking skills, as explained by Bloom (1956) and Anderson \& Krathwohl (2001). To nurture the ability to think critically, more time and more practice are definitely required.

\subsubsection{Inductive Reasoning}

Samples 12a and 12b are Student E's paragraphs in Writings 3 written in Japanese and Writing 4 written in English. In Sample 12a, he supported his main idea with the reason that a nation needs diversity. But he did not explain why diversity was important until the end of the paragraph, which gives the impression that his opinion is not clearly expressed. According to Hinds (1990), writing in Japanese, Korean, Chinese, and Thai follows a "quasi-inductive" style, which features a "delayed introduction of purpose". Organizing writing in this way "allows native speakers to understand the ideas but ... is lost on English-speaking readers" (p.98). Student E seems to have expected "that the minds of readers work in a very similar way to his or her own," as Hinds claimed (p.98).

\footnotetext{
Sample 12a (Writing 3 by Student E, originally written in Japanese and translated by the author)

I think that we should accept immigrants as a positive thing for the country. A nation needs diversity. Although many people have rejected accepting refugees for fear of letting terrorists into their country, the Prime Minister of Canada, Justin Trudeau, has declared that Canada should accept immigrants. In the speech he gave when he admitted immigrants, he stated that innovation will arise from diversity so they will accept immigrants. As Mr. Trudeau stated, the world needs diversity, so immigrants should be accepted.
}

In the next writing (Sample 12b), Student E wrote about globalization in English. Due to his low English proficiency, Writing 4 sounds childish, but besides that, he reasoned inductively, which would make it hard for an English reader to understand. Apparently it is very difficult to change ways of reasoning without a deeper 
learning of logic, something that cannot be earned only in the English language class. Cooperation among teachers from different fields is needed.

Sample 12b (Writing 4 by Student E, written in English)

Globalization makes our life better. Because globalization enlarges our possibility to get a foreign companies. If we can work at a good company, we get a lot of money. If there is a lot of money, our life becomes very rich. So, globalization makes our life better.

\section{Conclusion}

This study attempted to raise Japanese EFL lower-level students' awareness of the different rhetorical styles of Japanese and English and the logical paragraph organization used in written English, using explicit instruction and writing practice in both Japanese and English. An analysis of students' writings yields the following findings.

First, after receiving explicit instruction about the rhetorical differences between English and Japanese and about English paragraph structure, $36 \%$ of students in the study acquired an understanding of how to organize a paragraph logically using Japanese. However, 64\% of the students were still unable to write using logical structure, possibly due to the habit of Japanese rhetorical expression, which tends to be vague and circular. In teaching Japanese students to organize a paragraph logically, thinking and writing in Japanese were effective for some students but not for many other students. Further research is needed to find the best methods for teaching students to think and write logically and according to English paragraph structure.

Second, after explicit instruction repeated through the six sessions, 68\% of students acquired basic skills for writing opinions logically in spite of their low linguistic proficiency.

Third, students had greater difficulty in applying logical reasoning to the development of an opinion than in grasping the components and structure of a logical paragraph. In addition, some students were not able to decide on an opinion, either positive or negative, when writing in Japanese. This implies that thinking critically and making a decision is difficult for many Japanese students even when writing in Japanese.

Fourth, the quasi-inductive reasoning often used by Japanese people is hard for native English speakers to understand. Better methods for teaching different styles of logic need to be developed, which English language teachers alone cannot do. Further research and cooperation with teachers in other fields are needed.

Although any particular rhetorical style "is not a better nor a worse system than any other" (Kaplan, 1966, p.3), Japanese students definitely need to know that traditional Japanese rhetoric is quite different from that of other cultures, and both teachers and students must acknowledge the necessity of thinking and expressing oneself critically in order to live, work, and succeed in the twenty-first century.

\section{References}

Anderson, L.W., \& Krathwohl, D.R. (2001). Taxonomy for Learning, Teaching, and Assessing: A Revision of Bloom's Educational Objectives. New York: Longman.

ATC21S. (2012). 21 $1^{\text {st }}$ Century Skills. Retrieved from http://www.atc21s.org/

Atkinson, D. (1997). Critical approach to critical thinking in TESOL. TESOL Quarterly, 31(1), 71-94. https://doi.org/10.2307/3587975

Bloom, B.S., Englehart, M.B., Furst, E.J., Hill, W.H., \& Kratwohl, O.R. (1956). Taxonomy of educational objectives: The classification of educational goals Handbook 1: The cognitive domain. New York: Longman.

Davidson, B.W. (1995). Critical Thinking Education Faces the Challenge of Japan. Inquiry: Critical Thinking Across the Disciplines, 14(3), 41-53. https://doi.org/10.5840/inquiryctnews199514310

Fukuzawa, R. (1995). The path to adulthood according to Japanese middle schools. In T. Rohlen, \& G. LeTendre (Eds.), Teaching and Learning in Japan (pp. 295-322). NY: Cambridge University Press.

Hinds, J. (1990). Inductive, deductive, quasi-inductive: Expository writing in Japanaese, Korean, Chinese, and Thai. In U. Connor, \& A. M. Johns (Eds.), Coherence in Writing: Research and Pedagogical Perspectives (pp. 87-110). Alexandria, VA: TESOL.

Hirose. (2003). Comparing L1 and L2 organizational patterns in the argumentative writing of Japanese EFL students. Journal of Second Language Writing, 181-209. 
https://doi.org/10.1016/S1060-3743(03)00015-8

Kaplan, R.B. (1966). Cultural thought patters in inter-cultural education. Language Learning, 16(1-2), 1-20. https://doi.org/10.1111/j.1467-1770.1966.tb00804.x

McKinley, J. (2013). Displaying critical thinking in EFL academic writing: a discussion of Japanese to English contrastive rhetoric. RELC Journal, 44(2), 195-208. https://doi.org/10.1177/0033688213488386

Mulvay, B. (2016). Writing instruction: What is being taught in Japanese high schools, why, and why it matters. The Language Teacher, 40(3), 3-8.

Nakamura, A. (1983). Nihongo no retorikku [Japanese Rhetoric]. Tokyo: Chikuma.

National Institute for Education Policy Research. (2014). Daigakusei no gakushuu joukyou ni kansuru chousa ni tuite [Investigation of university students' learning]. Retrieved from https://www.nier.go.jp/04_kenkyu_annai/pdf/gakushu-jittai_2014.pdf

National Institution for Youth Education. (2017). Koukousei no benkyou to seikatu ni kannsuru ishiki chousa [Survey on high school students' study and life]. Retrieved from http://www.niye.go.jp/kanri/upload/editor/114/File/benkyou.pdf

Ohmae, K. (2003). Shitsumon suru chikara [Ability to ask questions]. Tokyo: Bungei Shunju.

Ohtani, Y. (2007). Nihonjin ni totte eigo towa nani ka [What is English for Japanese?]. Tokyo: Taishukan.

Oi, K. (1999). Comparison of argumentative styles: Japanese college students vs. American college students-An analysis using the Toulmin Model. JACET Bulletin, 30, 85-102.

Okada, R. (2015). Thinking in the Japanese classroom. Journal of Modern Education Review, 5(11), 1054-1060. https://doi.org/10.15341/jmer(2155-7993)/11.05.2015/004

Okada, R. (2017). Conflict between Critical Thinking and Cultural Values: Difficulty Asking Questions and Expressing Opinions in Japan. Asian Education Studies, 2(2), 2424-9033. https://doi.org/10.20849/aes.v2i1.122

Rear, D. (2012). The Dilemma of "Critical thinking" Conformism and Non-Conformism in Japanese Education Policy. In T. Iles, \& P. Matanle (Eds.), Researching Twenty-First Century Japan: New Directions and Approaches for the Electronic Age (pp. 119-135). Maryland: Lexington Books.

Reischauer, E.O. (1977). The Japanese. Tokyo: Tuttle Company.

Stapleton, P. (2002). Critical thinking in Japanese L2 writing: rethinking tired constructs. ELT Journal, 56(3), 250-257. https://doi.org/10.1093/elt/56.3.250

Yoshida, K. (2008). TEFL in Japan: An Overview. AILA Presentation. Retrieved August 25, 2008, from http://citeseerx.ist.psu.edu/viewdoc/download?doi=10.1.1.552.3363\&rep=rep1\&type=pdf

Yoshida, K. (2013). Tashikana komyunikeishon nouryoku wo ikusei suru eigo kyouiku no arubeki sugata [Instruction to nurture communication ability in English]. ELEC Bulletin, 120, 2-9.

\section{Copyrights}

Copyright for this article is retained by the author(s), with first publication rights granted to the journal.

This is an open-access article distributed under the terms and conditions of the Creative Commons Attribution license (http://creativecommons.org/licenses/by/4.0/). 